\title{
Fine needle aspiration cytology in a palpable breast lesion
}

\author{
Shrestha $\mathrm{A}^{1}$, Chalise $\mathrm{S}^{1}$, Karki $\mathrm{S}^{1}$, Shakya $\mathrm{G}^{1}$ \\ ${ }^{1}$ Department of Pathology, Institute of Medicine, Trivuwan University Teaching Hospital, Kathmandu, Nepal
}

\section{Keywords:}

Fine needle aspiration cytology; Breast lesion; Breast cancer; Fibroadenoma

\begin{abstract}
Background: Breast cancer is the common malignant lesion in women. Fine needle aspiration cytology has high sensitivity and specificity and is a simple, rapid and safe method to diagnose breast lesions. The aim of the study was to categorize breast lesions and correlate the Fine needle aspiration cytology diagnosis with histopatholoical findings.
\end{abstract}

Materials and Methods: This was a retrospective study done in department of Pathology of Institute of medicine, Trivuwan university teaching hospital, from January 2007 to December 2010. There were 1403 FNAC cases and 469 histopathology cases. Fine needle aspiration correlation with histopathology was done in 249 cases. All the cases were categorized according to risk for cancers: Unsatisfactory sample, Inflammatory breast disease Benign proliferative breast disease without atypia, Benign proliferative breast disease with atypia, Suspicious for malignancy and Malignant lesions.

Results: Benign breast lesions were common in the age group of 21-30 years and malignant breast lesion common in the age of 41-50 years of age. In our study fibroadenoma was most common benign lesion and ductal carcinoma was the most common malignant lesion. The sensitivity and specificity of FNAC for malignancy were found to be $98.2 \%$ and $98.5 \%$ respectively.

Conclusion: Fine needle aspiration cytology is highly sensitive and specific technique for diagnosis of most of the malignant and benign breast lesions.

\section{INTRODUCTION}

Breast cancer is the leading cause of morbidity and mortality. ${ }^{1,2}$ There is wide variety of breast pathology. It has been postulated that inflammatory breast disease and non proliferative breast disease do not increase the risk of cancer. Proliferative breast disease without atypia and with atypia confers mild and moderate risk respectively, whereas carcinoma in situ is associated with substantial risk

\section{Correspondence:}

Dr. Anjan Shrestha, $M D$

Department of Pathology, Institute of Medicine, Trivuwan University Teaching Hospital, Kathmandu, Nepal

Email:Anjan77@yahoo.com if untreated. ${ }^{3}$

There are different preoperative diagnostic modalities for breast pathology. Fine needle aspiration cytology (FNAC) is sensitive, simple, cost-effective, less traumatic and rapid method. FNAC may be used for palpable or non palpable and benign or malignant breast lesions. Palpable lesions may be either solid or cystic and non palpable lesions are detected by radio imaging study. ${ }^{1}$

The aim of this study was to find out the common causes of breast lesions and its risk categorization for development of cancer and to conduct cytohistological correlation. 
Table 1A: Benign lesions with no risk of cancer.

\begin{tabular}{lc}
\hline Diagnosis & No. of Cases \\
\hline I.Unsatisfactory sample & 27 \\
\hline II. Inflammatory breast lesion & - \\
\hline Breast Abscess & 53 \\
Mastitis & 68 \\
Fat necrosis & 6 \\
\hline Parasits: Filariasis, Cysticercosis & 3 \\
\hline Duct ectasia & 1 \\
\hline III.Nonproliferative breast disease & \\
\hline Fibrocystic change and simple cyst & 262 \\
\hline Epithelial hyperplasia, mild & 11 \\
\hline IV. Miscellaneous breast lesion & \\
\hline Benign mesenchymal lesion & 4 \\
\hline Lactational change/Galactocele & 44 \\
\hline Gynaecomastia & 37 \\
\hline Lipoma & 31 \\
\hline Sebaceous cyst & 4 \\
\hline Lymphadenitis & 9 \\
\hline Mucocele & 3 \\
\hline Axillary breast tissue & 11 \\
\hline No evidence of malignancy & 44 \\
\hline Total & $\mathbf{6 1 8}$ \\
\hline
\end{tabular}

Table 2A: Lesions with no risk of cancer

\begin{tabular}{|c|c|}
\hline \multicolumn{2}{|l|}{ I.Inflammatory breast lesions } \\
\hline Breast Abscess & 11 \\
\hline Mastitis & 28 \\
\hline Fat necrosis & 3 \\
\hline Duct ectasia & 8 \\
\hline \multicolumn{2}{|l|}{ II. Miscellaneous } \\
\hline Skin lesions & 5 \\
\hline Gynaecomastia & 36 \\
\hline Lipoma & 3 \\
\hline Lymphadenitis & 4 \\
\hline Fibrous mastopathy & 1 \\
\hline Galactocele & 1 \\
\hline Mesenchymal lesions & 3 \\
\hline Axillary breast tissue & 5 \\
\hline III.Nonproliferative breast disease & - \\
\hline Fibrocystic change & 26 \\
\hline Total & 134 \\
\hline
\end{tabular}

Table 1B: Benign lesion with mild and moderate risk for cancer .

\begin{tabular}{lc}
\hline Diagnosis & No. of Cases \\
\hline I.Proliferative breast disease without atypia & \\
Epithelial hyperplasia, moderate & 11 \\
\hline Adenosis & 128 \\
\hline Papilloma & 6 \\
\hline Fibroadenoma & 451 \\
\hline Phylloedes tumor, benign & 3 \\
\hline $\begin{array}{l}\text { II. Proliferative breast disease with } \\
\text { Atypia /Atypical but benign }\end{array}$ & 11 \\
\hline Total & $\mathbf{6 1 0}$ \\
\hline
\end{tabular}

Table 1C: Suspicious and malignant lesions

\begin{tabular}{|c|c|}
\hline Diagnosis & No. of Cases \\
\hline II.Suspicious for malignancy & 36 \\
\hline \multicolumn{2}{|l|}{ III.Malignant breast lesion } \\
\hline Ductal carcinoma & 124 \\
\hline Lobular carcinoma & 3 \\
\hline Medullary carcinoma & 4 \\
\hline Mucinous carcinoma & 3 \\
\hline Adenosquamous carcinoma & 3 \\
\hline Metaplastic carcinoma & 1 \\
\hline Atypical carcinoid tumor & 1 \\
\hline Total & 175 \\
\hline
\end{tabular}

Table 2B: Lesions with mild and moderate risk of cancer

\begin{tabular}{lc}
\hline $\begin{array}{l}\text { I.Proliferative breast disease without } \\
\text { atypia }\end{array}$ & No. of Cases \\
\hline Epithelial hyperplasia & 14 \\
\hline Adenosis & 22 \\
\hline Papilloma & 2 \\
\hline Tubular adenoma & 3 \\
\hline Fibroadenoma & 135 \\
\hline Phyllodes Tumor, benign & 4 \\
\hline II. Proliferative breast disease with atypia & - \\
\hline Atypical ductal hyperplasia & 2 \\
\hline Mucocele with ADH & 1 \\
\hline III. Miscellaneous & - \\
\hline Adenomyoepithelioma & 1 \\
\hline Total & $\mathbf{1 8 4}$ \\
\hline
\end{tabular}




\section{MATERIALS AND METHODS}

This was a retrospective study done over a period of four years from January 2007 to December 2010, in the Department of Pathology, Institute of Medicine, Tribhuwan University Teaching Hospital. Fine needle aspiration (FNA) was done with a 21 or 23 gauge needle attached to a $10 \mathrm{cc}$ airtight disposable syringe. The sample was obtained with aspiration and non aspiration techniques with minimum passes to minimize hemorrhage. Samples were smeared onto glass slides and fixed as necessary. In cystic lesions after aspiration of fluids the lesion was again aspirated. The fluid was centrifuged and the taken for smears. Wet-fixed

Table 2C: Histology of Malignant breast lesion

\begin{tabular}{|c|c|}
\hline Malignant lesions & No. of Cases \\
\hline Ductal carcinoma & 128 \\
\hline Lobular carcinoma & 1 \\
\hline Medulallary carcinoma & 5 \\
\hline Mucinous carcinoma & 3 \\
\hline Adenosquamous carcinoma & 7 \\
\hline Metaplastic carcinoma & 2 \\
\hline Infiltrating papillary carcinoma & 2 \\
\hline Carcinosarcoma & 1 \\
\hline Angiosarcoma & 1 \\
\hline Squamous cell carcinoma & 1 \\
\hline Phyllodes tumor, malignant & 1 \\
\hline Total & 152 \\
\hline
\end{tabular}

smears were stained with Papanicolaou stain, while airdried smears were stained with Giemsa stain.

During the period of study, breast lesions were interpreted according to the risk of developing cancer. According to National cancer institute consensus conference on breast FNA, categorization of breast lesions are: Unsatisfactory, Benign, Atypical probably benign, suspicious probably malignant and Malignant. Sensitivity, specificity and test efficiency were calculated using SPSS 11 software.

\section{RESULTS}

A total of 1403 FNAC cases were collected with detail radiological and clinical findings from pathology records. Histopathology examination of breast pathology was found in total of 469 cases. The FNAC report was correlated with the final histopathology report in 249 cases. The maximum number of cases was in the age group of 21-30 years in benign breast lesion and in the age group of 41-50 years in malignant breast lesion. Among them only $0.8 \%$ cases were male while $99.2 \%$ were female. Out of 1403 cases benign lesion with no risk factor, including unsatisfactory samples and parasitic lesions like filariasis(fig.1) and cysticercosis were 618 . Benign lesion with mild and moderate risk for cancer were 610 cases, suspicious for malignancy were 36 cases and malignancy were 139 cases. The details of these lesions are in Table 1A, 1B and 1C respectively.

Most common cases was fibroadenoma (32.1\%) followed by fibrocystic change and adenosis in benign breast lesion. Ductal carcinoma (8.8\%) was the commonest

Table 3: FNAC and Histopathology correlation.

\begin{tabular}{|c|c|c|c|c|c|c|c|c|c|c|c|c|c|c|}
\hline \multirow[b]{3}{*}{ FNAC } & \multicolumn{14}{|c|}{ Histopathology } \\
\hline & \multicolumn{5}{|c|}{ Benign } & \multicolumn{8}{|c|}{ Malignant } & \multirow[b]{2}{*}{$\begin{array}{l}\text { No. of } \\
\text { cases }\end{array}$} \\
\hline & Mes & IBD & NPBD & $\begin{array}{c}\text { BPBD } \\
\text { No } \\
\text { atypia }\end{array}$ & $\begin{array}{l}\text { BPBD } \\
\text { atypia }\end{array}$ & Sus & DC & LC & MC & MuC & CS & AS & MeC & \\
\hline Mes & 2 & & & & & & & & & & & & & 2 \\
\hline IBD & 1 & 19 & & & & & & & & & & & & 20 \\
\hline NPBD & & & 13 & 5 & & & & & & & & & & 18 \\
\hline $\begin{array}{l}\text { BPBD no } \\
\text { atypia }\end{array}$ & & 2 & 10 & 81 & & & & & & & & & & 93 \\
\hline $\begin{array}{l}\text { BPBD } \\
\text { atypia }\end{array}$ & & & & & 2 & & 1 & & & & & & & 3 \\
\hline Sus & & & & & 1 & & 11 & & & & & & & 12 \\
\hline DC & 1 & & & & 1 & & 77 & & & & & 2 & 1 & 82 \\
\hline LC & & & & & & & 1 & 1 & & & & & & 2 \\
\hline MC & & & & & & & 2 & 1 & 9 & & & & & 12 \\
\hline MuC & & & & & 1 & & 1 & & & 3 & & & & 5 \\
\hline
\end{tabular}

Mes: Mesenchymal breast disease, IBD: Inflammatory breast disease, NPBD: Non proliferative breast disease, BPBD: Benign proliferative breast disease, DC: Ductal carcinoma, LC: Lobular carcinoma, MC: Medullary carcinoma, MuC:Mucinous carcinoma, AS: Adenosquamous Carcinoma, MetC: Metaplastic carcinoma. 


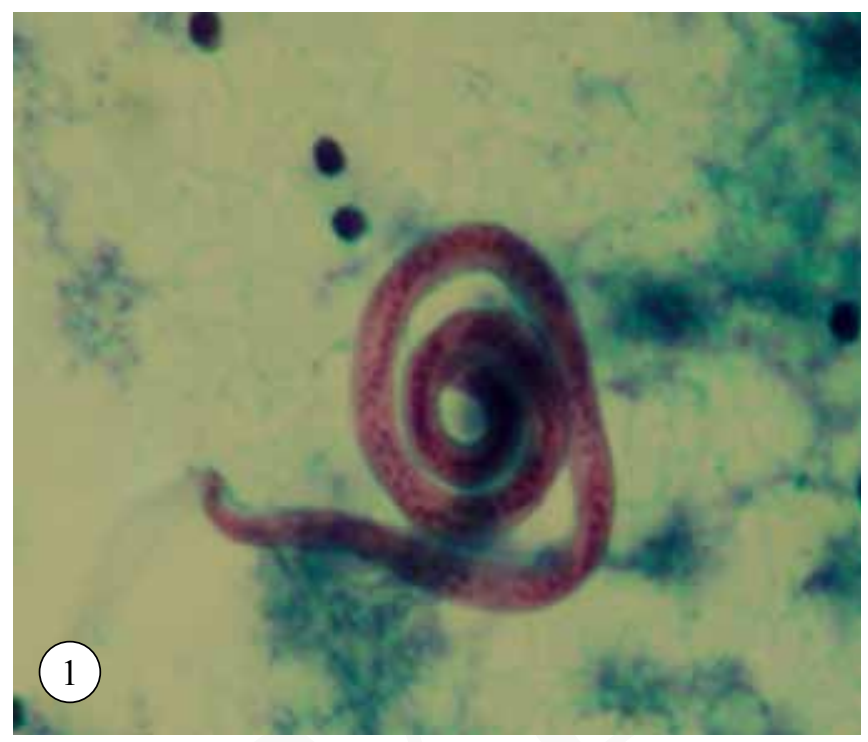

Figure 1: Fine needle aspiration smear showing microfilaria (Papanicolaou stain, X10)

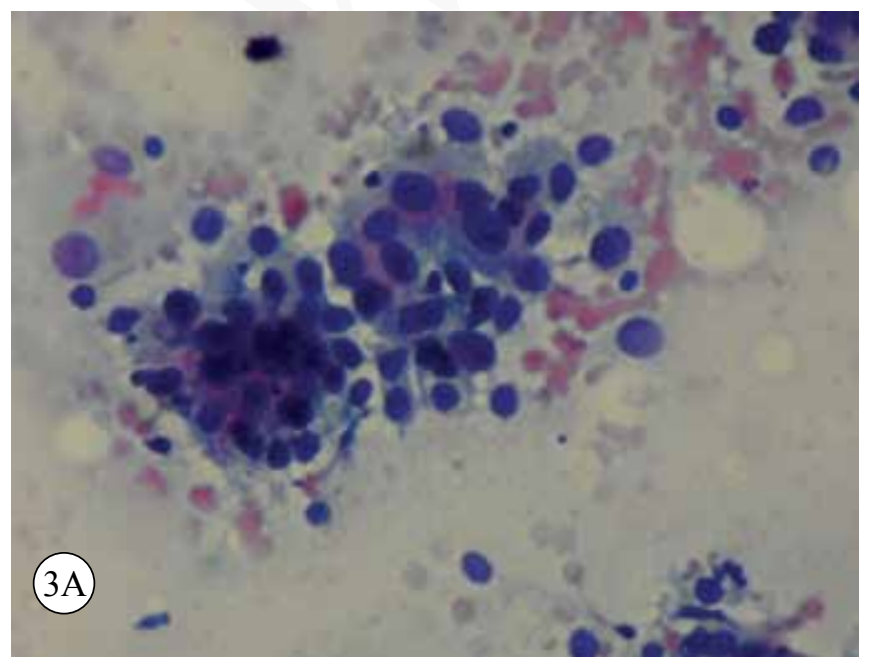

Figure 3A: Smears showing loosely arranged pleomorphic tumor cells (Papanicolaou stain, X200)

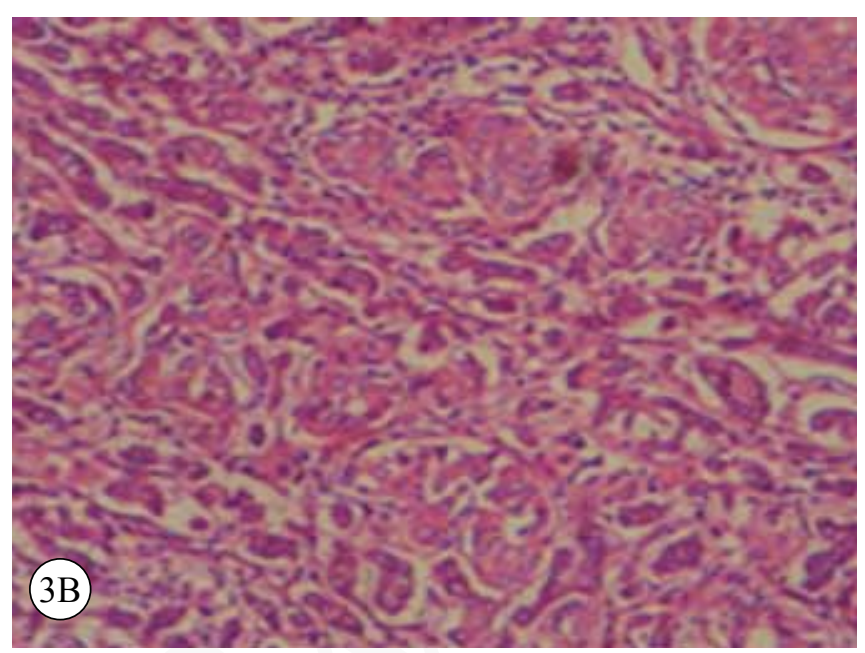

Figure 3B: Section showing Invasive ductal carcinoma arranged in glandular patterns and in cords (HE stain, X50)

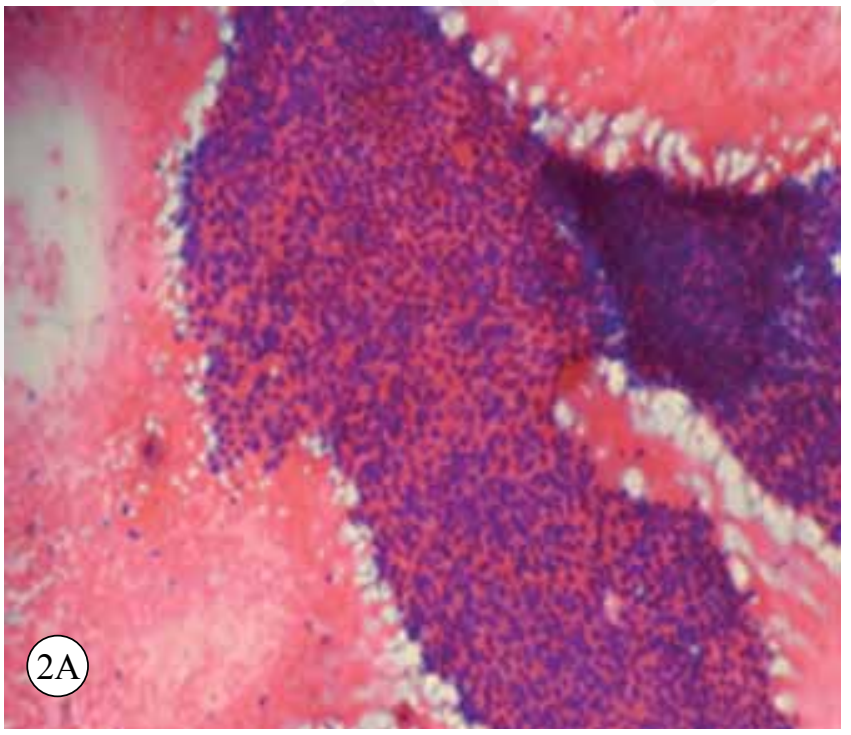

Figure 2A: Smears showing monolayered sheets of epithelial cells in branching pattern. (Wright stain, X10)

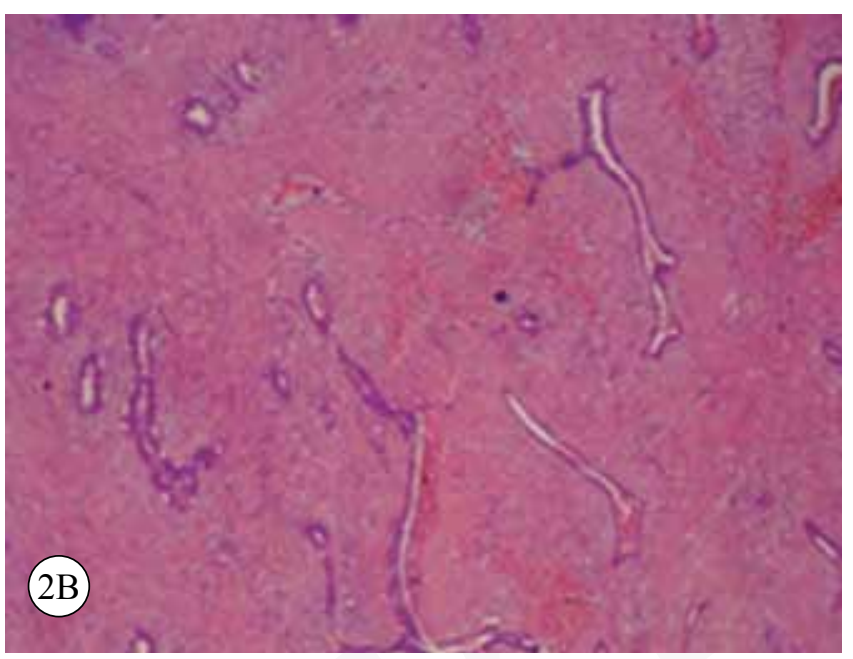

Figure 2B: Section showing proliferating ducts and stromal component. (HE stain, X20)

malignant breast lesion. There were chronic nonspecific, granulomatous and necrotizing granulomatous mastitis.

Out of 469 histological samples, 317 cases were benign breast disease and 152 cases were malignant lesions. Skin lesions were seborrhiec keratosis, Fibroadenoma was the commonest benign breast lesion and ductal carcinoma was the most common malignant lesions (Table 2A, 2B \&2C). FNAC correlation with histopathology is significant ( $\mathrm{P}$ value $=0.01$ ). The cytohistological correlation is shown in Table 3.

\section{DISCUSSION}

Breast carcinoma is common cancer among females in Nepal preceded by cervical cancer. ${ }^{4,5}$ Different studies have shown that the most common lesions are benign and needs 
only reassurance. ${ }^{5,6}$ Early screening and diagnosis of breast lesions and categorization into different groups of breast pathology is important. This can be helpful in prevention of cancer and in accurate management of the patients. Early diagnosis helps to prevent patients discomfort and anxiety. ${ }^{7,8}$

Fibroadenoma (fig. 2A and B) is the commonest lesion in the category of proliferative breast disease without atypia that has minimal risk for cancer development. Ferguson also reported most common benign breast lesion as fibroadenoma occurring before the age of 25 years of age. ${ }^{9}$

Singh $\mathrm{A}$ et $\mathrm{al}^{5}$ reported that invasive ductal carcinoma is the commonest breast malignancy and found in the age group of 41-60 years of age. The present study shows similar findings, the ductal carcinoma being the most common breast malignancy in the age group of 41-60 year of age (fig. 3A \& 3B).

In this study $1.7 \%$ cases were unsatisfactory. Sudarat et $\mathrm{al}^{10}$ found $4.2 \%$ of unsatisfactory smear i.e. fewer than five epithelial cell groups, which needs further repeat aspiration or needs core/incisional biopsy for analysis. Unsatisfactory sample can be due to insufficient experience of the pathologist, radiologist or clinician who perform FNA or due to nature of lesion itself. FNA sampling technique is equally important as sample interpretation in reaching the correct diagnosis. Provision of adequate sample and experienced pathologist can prove FNAC as highly reliable diagnostic tool. ${ }^{1}$

In comparative analysis of FNAC and histopathology diagnosis, we observed 5 cases of cytologically interpreted errors which were 3 cases of false positive and 2 case of false negative cases. Two false negative cases diagnosed as BPBD with atypia turn out to be malignant cases. In 3 false positive cases 2 were BPBD with atypia and 1 case was benign fibrous histiocytoma. Twelve cases diagnosed as suspicious for malignancy in FNA were considered as malignant in this study. In which one case was diagnosed as BPBD with atypia. FNAC of breast lesions is sensitive, specific, and highly accurate as the initial investigation of palpable breast lesions in tertiary hospital. ${ }^{11}$
Thus the FNAC smears have very high accuracy in diagnosis of breast lump. ${ }^{12,13}$

\section{CONCLUSION}

The FNAC of breast is cheap, safe and highly accurate preoperative method for diagnosis of breast lesions. Preoperative categorization of breast lesions is utmost important for management of the patient.

\section{REFERENCES}

1. Leopold G.koss, Editor. Koss Diagnostic cytology. 5th ed. Lippincott Williams \&Wilkins: Philadelphia; 2006. pp1081-84.

2. Muddegowda PH, Lingegowda JB, Kurpad RK, Konapur PG, Shivarudrappa AS, Subramaniam PM. The value of systematic pattern analysis in FNAC of breast lesions: 225 cases with cytohistological correlation. J cytol. 2011;28:13-9.

3. Kumar Abbas Fausto. Robbins and Cotran Editor. Robbins and Cotran Pathologic basis of disease. 7th ed. Elsevier: Philadelphia;2004. pp1121-30.

4. Pandey JS, Sayami G, Dali S et al. Fine needle aspiration cytology of breast lump in TUTH. JNMA 2002:41:388-91.

5. Manohar P, Adhikari RC, Sigdel B, Basnet RB, Amatya VJ. Present Cancer status in TU Teaching Hospital. JSSN 1992;2:16-23.

6. Singh A, Haritwal A, Murali BM. Pattern of breast lumps and diagnostic accyracy of Fine needle aspiration cytology; A hospital based study from Pondicherry,India. The internet journal of pathology 2011;11:2.

7. Hughes JE, Royle GT, Buchanan R, Taylor I: Depression and social stress among patients with benign breast lesion. Br J Surg 1986;73:997-9.

8. Ellman R, Angeli N, Moss S, Chamberlain J, Maguire P. Psychiactric morbidity associated with screening of bereast cancer. Br J Cancer 1989;60:781-4.

9. Ferguson CM, Powell RW. Breast masses in women. Arch Surg1989; $124: 1338$.

10. Sudarat N, Somneuk J, Siriwan T. Accuracy of FNAC from breast masses in Thailand. AJCP2009;10:623-6.

11. Nggada HA, Tahir MB, Musa AB et al. Correlation between histopathologic and fine needle aspiration cytology diagnosis of palpable breast lesions: a five-year review. Afr $\mathrm{J}$ med sci 2007;36:295-8.

12. Purasiri P, Abdalla M, Heys SD et al. A novel diagnostic index for use in the breast clinic. J R Coll Surg Edinb1996;41:30-4.

13. Kaufman Z, Shpitz B, Shapiro M, Rona R, Lew S, Dinbar A: Triple approach in the diagnosis of dominant breast masses: combined physical examination, mammography and fine needle aspiration. J Surg Oncol 1994;56:254-7. 